\title{
Dokumenti iz 15. stoljeća na talijanskom jeziku u prvom svesku Bartolijeva zbornika
}

\begin{abstract}
U samostanu franjevaca trećoredaca glagoljaša u Krku pohranjena je kopijalna knjiga koja sadrži prijepise dokumenata od 13. do 19. stoljeća, a obično se naziva Bartolijevim zbornikom. Taj je zbornik, naime, većim dijelom sastavio fra Feliks Marija Bartoli od 1740. do 1743., a drugi su ga poslije nastavili. Sastoji se od dvaju svezaka, koji ukupno broje preko četiristo obostrano ispisanih listova papira. U prvome svesku nalaze se dokumenti na latinskom i talijanskom jeziku, a u drugome ima i onih na hrvatskom, zapisanih glagoljicom. U ovom će se radu predstaviti i analizirati dokumenti iz 15. stoljeća napisani na talijanskom jeziku, pri čemu će se iznijeti i jezične osobitosti.
\end{abstract}

\section{O Bartoliju i njegovu zborniku}

Fra Feliks Marija Bartoli ${ }^{1}$ (Krk, 8. V. 1679. - Krk, 5. II. 1744.) započeo je svoje školovanje ušavši u samostan franjevaca konventualaca sv. Franje u Krku. Studij teologije završio je u Padovi 1711. Vršio je razne službe: gvardijana u Krku i Poreču, tajnika Provincije, kustosa za istarske samostane, provincijala. Od 1740. do 1743. bavio se prepisivanjem isprava krčkoga samostana, stvorivši tako dvosveščanu kopijalnu knjigu, odnosno katastik, koji se obično naziva Bartolijevim zbornikom. ${ }^{2}$ Nakon Bartolija drugi su prepisivači nastavili to djelo; stoga dokumenti u drugom svesku sežu do $1813 .{ }^{3}$ U prvome svesku nalaze se isprave na latinskom i talijanskom, a u drugome ima i onih na hrvatskom, zapisanih glagoljicom. Prijepisi isprava popraćeni su regestima, napomenama i zapisima na marginama na talijanskom jeziku. Bartoli dokumente nije poredao kronološki, već ih je prepisivao redom kako bi koji pronašao. ${ }^{4}$

1 U upotrebi su bili i drugi oblici njegova imena i prezimena: Felix Maria, Felice Maria, Blagoslav, Bartolić.

2 U katalogu samostanske knjižnice zbornik je zaveden pod naslovom „Cattastico documentato del monastero di Veglia dei Min. Conv. dal 1284 al 1781“.

3 Usp. GALOVIĆ 2009 i ROŠČIĆ 1983.

4 O tome je i sam Bartoli (fol. 230 ) napisao ovu napomenu: „Comecchè molti, anzi moltissimi Istromenti m'è riuscito estrarli da Publici Prottocoli esistenti nella Cancellaria dell Communità, pero avendoli trascritti in questo Libro in diversi tempi, così non è da meravigliarsi, se non sono registrati per successione di tempo, come sarebbe desiderabile, e come da me nel principio di 
$\mathrm{Na}$ fol. 2 prvoga sveska nalazi se Bartolijev naslov: Indice delle Scritture del Convento di San Francesco della Città di Veglia fedelmente copiate da me Frà Felice Bartoli Esprovinciale negl'Anni 1740, 1741 - 1743. Kasnije je na fol. 1 fra Bernardin Polonijo nadodao poduži naslov: ${ }^{5}$ Collectanea Bartoliana a Croatis Bartolijev Zbornik dicta, ab Auctore Patre Magistro Fratre Felice Maria Bartoli Veglensi, Ordinis Minorum Conventualium Ex-Provinciali, Veglae $=$ Krk, annis 1741-1743. Documentis de Bonis realibus Oneribusque piis Monasterii Minoritici Conventualis S. Francisci de Vegla provisa, rectius, in dorso involucri, , Cattastico " nuncupata. Pleno ergo titulo esto: Cattastico Documentato del Monastero di Veglia dei Minori Conventuali (dal 1284 al 1781) compilato dal Padre Maestro Felice Maria Bartoli Vegliese Esprovinciale nei Minori Conventuali. Volume I., di folii 286, comprendente gli anni 1284-1607. Veglia $=1741-43 .^{6}$

Dio dokumenata iz Bartolijeva zbornika objavljen je u više publikacija, pri čemu su neki objavljeni u cijelosti, a neki u obliku opširnih regesta. Tako je Ivan Črnčić (1867.) objavio šesnaest latinskih isprava iz Bartolijeva zbornika. ${ }^{7}$ Kasnije je Črnčić (1888.) objavio jednu talijansku ispravu i trideset latinskih (neke u cijelosti a neke u obliku regesta na latinskom). ${ }^{8}$ Mile Magdić (1900.) objavio je latinske isprave iz 14. stoljeća (jednu cjelovitu i devetnaest u obliku

questa fatica si era deliberato. Quello pertanto non ho potuto fare io, stante la mia pur troppo avanzata età di Anni 64. compiti, in questo stesso giorno 8. Maggio del 1743. Prego Dio venga perfezionato da altri sobbetti più Giovani. più Forti, e più abili di me. Faxit Deus.“

5 U svome prijepisu Polonijo (str. 23) iznosi da je, potaknut sadržajem i time što je na hrptu prvoga kodeksa napisana riječ „Cattastico“, dao „takozvanom Bartolijevu Zborniku ili Indeksu ovaj naziv: Catastico Documentato...".

6 Polonijo je također na nekoliko mjesta u zborniku nadopisao svoje napomene.

7 Donosimo popis isprava, navodeći Črnčićevu numeraciju i datum iz isprave: I. 2. 2. 1733., III. 8. 5. 1295., IV. 8. 1295., V. 3. 2. 1306., VI. 15. 9. 1323., VII. 22. 4. 1377., IX. 5. 11. 1402., X. 8. ?. 1410., XI. 27. 2. 1419., XII. 15. 5. 1419., XIII. 1. 9. 1419., XIV. 10. 6. 1421., XV. 8. 12. 1420., XVI. 8. 7. 1421., XVII. 10. 4. 1434., XXI. 12. 5. 1519.

8 Donosimo popis isprava objavljenih u ČRNČIĆ 1888., navodeći i njegove naslove ondje gdje postoje: 10. 7. 1248. Popis Krčke vlastele, 7. 2. 1300. Za bratovštinu sv. Frana u Krku, 13. 2. 1317., 10. 7. 1348. Znamenita oporuka, 22. 11. 1350. Knez Bartol izručuje krčkim Franovcem što im je pustila njegova teta Cecilija, 7. 3. 1351., 19. 8. 1362. Krčki sudci odsudjuju, da Klara de Virzolis ima platiti krčkim Franovcem njeki dug, 15. 1. 1368., 15. 6. 1370. Krčki sudci za nekakovo trsje odsudjuju da je totu franovačko, 22. 10. 1371., 8. 7. 1376., 15. 11. 1377., 6. 5. 1378., 29. 6. 1329. Vitez Mikula iz Hreljina očituje, da mu je knez Ivan Krčki itd. dužan 200 dukata, pak toga pol zapisuje Krčkim a pol Jerusolimskim Franovcem, 13. 10. 1394., 12. 12. 1397., 6. 5. 1400., 9. 1. 1405., 6. 2. 1407., 27. 2. 1418. Vid Kirinčić iz Baške zapisuje krč. franovcem četvrt nekakova vinograda, 8. 3. 1418., 8. 11. 1420., 2. 2. 1427., 9. ?. 1445. Knez Ivan Frankopan, uzdajuć se u svoju braću, daje nekomu Dujmu crkvicu na Glavotoku, 20. 10. 1471., 16. 10. 1488., 19. 10. 1488., 1501., 25. 6. 1502. Zaharija Garzoni, mletčanin, dostignuv po mletačkoj gospodi opatije sv. Lucije u Baški i sv. Lovrenca u Krku za uživanje, po poruku daje u najam sve dobro tih opatija, 26. 4. 1518., 2. 11. 1521. 
regesta). ${ }^{9}$ Neki su dokumenti objavljeni u Diplomatičkom zborniku Kraljevine Hrvatske, Dalmacije i Slavonije.

\section{Prijepis fra Bernardina Polonija}

Veći dio dokumenata, $\mathrm{tj}$. one koji se odnose na franjevce konventualce, prepisao je, krateći i prepričavajući dijelove te dodajući svoje komentare i objašnjenja, fra Bernardin Polonijo 1952. Taj se dvosveščani rukopis s kronološki poredanim dokumentima čuva u Arhivu Provincije franjevaca konventualaca u Zagrebu. ${ }^{10}$

Prva je stranica prvoga sveska podijeljena na dva stupca, pa je u lijevom stupcu naveden naslov na hrvatskom, a u desnom na latinskom. Naslov na hrvatskom glasi: „Bartolijev Zbornik Krčkih Isprava sveden na franovačke stvari uz maleno pripuštenje inostranih. Prepisao i po vremenu razredio dr. fr. Bernardin Polonijo fran. konventualac ex-provincijal. U Krku, 1952. Svezak I. ${ }^{\mathrm{i}}$ od god. 1248. do 1698." ${ }^{\text {"11 }}$ Drugi svezak započinje istim naslovom do dijela gdje je navedeno da su u njemu isprave „od g. 1701. do 1814.“.

Zatim u prvom svesku slijedi dio naslovljen „Napomene prepisivača čitatelju“, pri čemu su stranice također podijeljene na stupce, gdje je u lijevom stupcu tekst na hrvatskom, a u desnom na talijanskom. Ovdje Polonijo na 29 stranica isnosi podatke o povijesti samostana. Navodi da su „mala braća franovci konventualci“ napustili samostan i crkvu „sv. Frana“1781., nakon petsto godina, jer ga nisu imali s kime naseliti poslije smrti fra Vincenca Carobbija 3. travnja 1781. Napominje da se na sličan način potkraj 18. stoljeća ugasilo još osam samostana njihove provincije, u mjestima Ižula, Buzet, Labin, Ilovik, Rab, Pag, Trogir i Kotor.

Objašnjava da je do takvoga ishoda dovela mletačka vlast time što je 1767. zabranila redovnicima primanje novaka, što je izmijenila 1784., dopustivši da se nakon smrti jednog redovnika može primiti novi. Te su mjere bile znatno ublažene za „malu braću opservante Dalmatinske Zagore, jer su bili dušobrižnici, jedini u onom kraju“ i za „franovce III reda glagoljaše baš zato što su bili glagoljaši, pa ih je mudra Venecija štedjela, da inače ne razjari protiv sebe hrvatski puk Istre i Dalmacije“. Nadalje navodi da je nakon smrti posljednjeg konventualca u krčkom

$9 \quad$ Magdić izražava žaljenje da je rukopis uspio dobiti na korištenje samo na jedan dan, pa nije mogao prepisati više isprava. Objavio je u cijelosti samo oporuku krčkoga kneza Nikole Frankapana od 22. 4. 1377., dok je regeste sastavio za isprave sa sljedećim datacijama: 10. 1. 1305., 8. 3. 1318., 14. 12. 1320., 13. 4. 1326., 5. 10. 1342., 5. 12. 1342., 10. 10. 1350., 7. 3. 1351., 12.3. 1363., 15. 11. 1364., 5. 5. 1367., 6. 1. 1368., 4. 9. 1374., 18. 11. 1374., 14. 2. 1377., 6. 5. 1378., 21. 1. 1388., 13. 10. 1394., 7. 1. 1398.

10 Prvi svezak obuhvaća 352, a drugi 182 stranice.

11 U latinskoj verziji glasi: „Collectanea Bartoliana Documentorum Veglensium ad franciscalia paucis alienis admissis redacta. Transumpsit et chronologice disposuit p. magr. Bernardinus Polonijo ex-Provlis Ord. Min. Conv. Veglae, 1952. Volumen I. ${ }^{\text {um، }}$. 
samostanu, mletački dužd 28. travnja 1763. izdao dukal, kojim je krčkom providuru i krčkom biskupu naložio da samostan u Krku predaju trećorecima glagoljašima „uz dužnost da oci trećoreci poučavaju hrvatsku mladež otoka, eda ova ne mora za svoju višu izobrazbu pohađati hrvatske škole van mletačke države“.

Zatim opisuje Bartolijev zbornik, uz napomenu da Bartoli nije najsretnije prepisao najstarije isprave, što vjerojatno nije ni mogao zbog njihove istrošenosti, ali da su njegovi prijepisi danas dragocjeni jer su mnoge isprave uništene u požarima. ${ }^{12}$

Polonijo nadalje iznosi kako je toga ljeta proveo pedeset i šest dana u Krku, tražeći u samostanskom arhivu ono što se odnosi na konventualce; navodi i druge zbirke isprava koje je ondje pronašao. Smatra da je Bartolijeva namjera bila popisati i dokumentima dokazati samostanska dobra i terete te da bi stoga ovu zbirku najprikladnije bilo nazivati katastikom. Također iznosi da je prethodni samostanski katastik 1609. izradio o. Bonaventura Rinaldis, ali više nije odgovarao stvarnom stanju, pa je zato 21. ožujka 1686. generalni povjerenik provincije naložio krčkom gvardijanu da sastavi novi katastik, ali tada se nitko nije prihvatio toga posla, nego tek nešto kasnije sâm Bartoli.

\section{O dokumentima na talijanskom jeziku u zbirci}

U prvome svesku Bartolijeva zbornika ima oko 150 zapisa na talijanskom jeziku (oko četvrtine opsega sveska); najveći je dio iz 16. stoljeća, tri su iz 15. te osamnaest iz 17. stoljeća. Uglavnom je riječ o djelomično ili cjelovito prepisanim dokumentima, a neki se donose samo u obliku regesta. Osim toga, u nekoliko slučajeva nalazimo da je samo dio dokumenta na talijanskom, dok je ostatak na latinskom.

\section{Dokumenti na talijanskom jeziku iz 15. stoljeća}

Najstariji je dokument na talijanskom jeziku u ovoj zbirci privilegij kneza

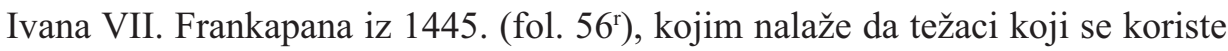
nekim njegovim posjedima moraju davati desetinu braći u samostanu sv. Marije na Glavotoku. ${ }^{13}$ Nakon Bartolijeva regesta slijedi napomena na talijanskom da je ovo prijepis iz jednoga civilnog procesa, a zatim i druga napomena na latinskom, u kojoj piše da je tekst prenesen iz izvornika „de Slavo in Latinum“ te da je to

12 Polonijo donosi podatke da je ured odvjetnika Balsama Franceschinija, zajedno s mnogim spisima samostana, crkava, kaptola i biskupije, izgorio 1667. ili 1668. te da je arhiv krčke općine uništen u požaru 1738., a arhiv krčkoga suda 1768.

13 Ovaj dokument nalazi se i u ČRNČIĆ 1888: 17-18. Naša se transkrpcija ponešto razlikuje od njegove. 
napravio mletački bilježnik Daniele Terzago. ${ }^{14}$ Prema tome, ako Latinus shvatimo kao „talijanski“"15, to znači da je dokument preveden s hrvatskoga na talijanski, a ako Latinus shvatimo kao „latinski“, tada je najprije preveden na latinski, pa tek poslije na talijanski. Tekst dokumenta glasi:

„Noi Conte Zuanne de Frangipanibus de Veggia, Segna, Modrusia etc. significhiamo per questa nostra Lettera aperta, et in perpetual memoria, come Noi volendo Magnificar li Nostri Diletti Fradelli, et in nostro Dominio, et similmente le Capelle, over le Chiese, qual sono nel nostro Dominio, acciochè siano similmente bonificade le nostre Capelle, specialmente quelle, che sono nell'Isola di Veglia. Havemo dado la Capella della Beata Vergine Maria chiamata di Capo dell'Isola, à Doimo et à suoi heredi perpetualiter senza alcun impedimento predetto; con fiducia de nostri Fedeli Diletti Fratelli, e de i nostri Successori, con questa condition, che Lui possa galder li Terreni di questa Giesia, et che abbia dar da mo avanti sempre nel zorno di san Zorzi una Vedella, à colui, à chi fosse dada la Giesia dalli nostri diletti Fradelli, e da Nui similmente, et che le debbia dar la decima di tutto quello, che nascesse in questi Terreni à quello el qual avesse la Giesia nelle man. Item se quando esso Doimo, over suoi heredi piantasse Vigne, et che sia tenudi à dar la decima, à cui fosse la Giesia nelle man: et questo à cui li nostri diletti Fradelli, e Nui, over li nostri Successori desse, ò donasse questa Giesia sol non possa lo dito Doimo, over li suoi heredi descazar, ne azonzer altra servitù ne à Lui, ne à suoi heredi, eccetto come di sopra se contiene; et questo havevo fatto, perche era deserto, non era alcuna intrada à questa Giesia. Item sopra questo, come Nui inquirissimo con verità dai nostri huomini dabene, che chi fosse che per invidia, ò per propria volontà fesse pascolar, over danno facesse à questa Giesia, chel rimanga in Ducati cinquanta per l'antiqua consuetudine; et similiter Noi Confermemo tutto questo con il nostro sigillo consueto questa nostra Lettera sub Anno Domini 1445. Datum Veglę Die 9 mensis..." ${ }^{\text {"16 }}$

Zatim slijedi potvrda na latinskom, u kojoj krčki kancelar Filotis Dardis iznosi da je iz spomenutoga procesa prepisao taj dokument 18. ožujka 1564. Na kraju se nalaze potvrde krčkoga vicekancelara i bilježnika.

$\mathrm{Na}$ fol. $74^{\mathrm{r}}$ nalazi se ulomak oporuke ${ }^{17}$ Elizabete Frankapan, žene kneza Ivana, kojom ostavlja stotinu zlatnih dukata fratrima u Krku, za što oni moraju zauvijek na dan njene smrti održavati pjevanu misu. Prvi je dio zapisa na latinskom te iz njega, između ostaloga, saznajemo da je oporuka sastavljena 19. kolovoza 1484. u Veneciji. ${ }^{18}$ Zatim slijedi sam ulomak oporuke na talijanskom, u kojem se navode riječi ostaviteljice:

14 Daniele Terzago bio je javni bilježnik u Krku od 1488. do 1504. (ČRNČIĆ 1888: 6).

15 U Lexicon Latinitatis (str. 644) uz ovu se riječ navodi značenje „talijanski“.

16 Ovdje je prepisivačeva napomena, koja kazuje da se ne vidi mjesec jer ga je pokrio pečat: „Hic nuncupatur sigillum, et non potest legi cuius mensis sit“".

17 Latinski je izraz za ulomak oporuke punctum testamenti, a talijanski punto del testamento.

18 Oporuku je sastavio venecijanski bilježnik Girolamo (Hieronymus) Bonicardi. 
„Et si lasso, che il mio Signor debbia dar al Conte Martin Motsenich Ducati 400. della mia dota; et etiam alla Iesia de San Francesco de Vegia debbia dar della mia dota Ducati cento d'Oro; et volio, che li Frati del dito monasterio siano obligati ogni Anno in perpetuo cantar Messa nel dì del mio transito."

Nakon ove oporuke na istoj stranici nalazimo upute koje je gvardijan krčkoga samostana uputio svome zastupniku u Veneciji:

„Arecordo à Vostra Reverenda Paternità d'istituir uno Procurador, et Avocato per el Logo de Vegia in Venezia, et questo per addi mandar li cento Ducati lassati per la Madonna fò del Conte Zuanne da Vegia.

Item. Chel abbia comparer, e avvocar per le Cose fò, e donò Gospa Anconia de Vegia al Convento.

Item. Chel abbia à dimandar una dichiaration dalla Illustrissima Signoria delli Beni, che per el Signor Conte Zuanne sono stati donati in premio de lor mercede alli suoi servidori, come li Beni Stabili Lui si à donato alli ditti sui servi in premio del suo servio, sicome Terre lavorate, e non lavorate, Pascoli, Vigne, Campi, Boschi, Case, Casali, Orti in la Terra, etiam fora della Terra. La qual Cosa è stata molto disonesta à tuor dalla Iesia, e dar alli soui stipendiarii, et à quelli li hà fatto privileggio contra la Iesia. Non dimandamo excepto quello, che per scripture e bone testimonianze se puol approvar.

Item. Per sovvenzione del Convento abbiamo un poco d'Animali, in tutto ne son cento, el Signor non soleva Datio nessuno del Convento, si preghemo quella non noia imponer tal'angaria alla Iesia.

Item. Adimandemo gratia, che ne noia donar ogni Anno dalla Camera, per l'Amore de Dio quattro Stera de Sal, overo di poterlo condur de fuora dell'Isola per uso del Convento; ò tutto quanto a Lor piaserà. Et questo per la gran povertà del Convento sovranominato.

Item. Tutte le spese, che accaderà voio siano sodisfatte per el Convento, e cosi ve prego ve piaqua de solicitar, e avisarme de tutto zò avreti fatto; e se caso bisognasse qualche informatione de scripture, e testimonii dal canto de quà, per Vostre me darete aviso.

Item. Se diti Denari per aventura se rescodesseno, che li siano mandati in man del Provedador se attroverà al presente, et per fideli messi. Con saputa delli Procuradori, e del Guardian s'attroverà al presente.

Li Denari se de vacar della Dota, secondo el testamento, e qui fà bisogno batter el ferro. Item. Della provisione restava aver Madonna della Camera.

Item. Ancora delli sui beni stabili la insuso la Isola de Vegia; per uno de questi modi fà bisogno rescoder li diti Denari.

Per mi Frat'Honofrio de Pirano Guardian del Convento de Vegia me arecomando ala Vostra Reverenda Paternità, e si ve sì racomandato el ditto Convento."

Polonijo ovoj oporuci posvećuje nekoliko stranica (85-89), iznoseći i događaje koji su prethodili samoj oporuci.

Kronološki zadnji zapis na talijanskom (fol. 57v) odnosi se na oltar sv. Bernardina u crkvi sv. Frane. Taj je zapis sažetak izvornoga latinskog dokumenta iz 
1478. Nakon Bartolijeve napomene da je riječ o prijepisu s treće folije Katastika samostana sv. Frane u Krku iz $1609 .{ }^{19}$, slijedi ovaj tekst:

\begin{abstract}
„L'Altare di San Bernardino nella Chiesa nostra di San Francesco, vicino à quello dè tre Maggi, fù addottato nel 1459. da Madonna Antonia relitta del quondam Jacomo, e Figlia del quondam Domenico di Tegnaura di Veglia in vita sua di lire 8. di piccoli all'Anno, et dopo la morte sua di tutta la sua Casa posta in Contrata di San Cristoforo di Pianca, e di San Jacomo da Corte, la qual dopo la morte della predetta fù posta in Lite dagl'heredi suoi nel 1484. sotto il Regimento del Clarissimo Signor Pietro Colbo Proveditor dignissimo di Veglia, et sempre tutti di tempo in tempo pacificamente l'anno goduta, et posseduta, et per un tempo l'ebbe à Livello il quondam Misser Giorgio Hisco, poi il quondam Signor Nicolò Zutinis, e dopo di Lui il quondam suo Figlio Misser Bernardin Zutinis, et pagava lire de piccoli ventidue, vale L 22. Poi questa Casa fu permutata in un Pascolo dell'Isola di Cherso detto della Contrada di Orlaz, il qual Pascolo, hora tengono gl'Eredi del quondam Gregorio Suscich, e pagano in perpetuo al nostro Convento di San Francesco di Veglia, termine à San Pietro, lire ventidue de piccoli, vale L 22.

La permuta appar per istromento fatto in Cherso, et registrato negl'Atti della Cancellaria di Cherso nel 1563., et la copia è trà le scritture del Convento in Carta Pecorina, autenticata dal Clarissimo allora, et Magnifico signor Conte, e Capitano di Cherso, et Ossero, et estratto da Misser Bernardino Lucio Nodaro, et allora Vice Canceliere nella Cancellaria di Cherso. Che la detta Casa fosse stata lasciata per dote dell'officiatura, appar per istromento di Misser Bartolomio di Veglia Giudice Ordinario del 1478. adi 15 . Novembris.“
\end{abstract}

Polonijo (str. 74-75, br. 44) donosi samo prvi dio u prijepisu te ukratko iznosi sadržaj ostatka.

\title{
Jezične karakteristike dokumenata
}

Analizirani su dokumenti napisani na talijanskom jeziku onoga vremena s mletačkim elementima. Mletačka Republika u početku se koristila svojim mletačkim idiomom u službenim dokumentima, međutim od 15. stoljeća počinje prijelaz prema toskanskom, koji je gotovo u isključivoj uporabi od druge polovine 16 . stoljeća. ${ }^{20}$ Nesumnjivo je da su notari i ostali stvaratelji dokumenata mletački rabili u svakodnevnoj komunikaciji, pa je stoga i očekivano da će se u njihovim zapisima naći mletački elementi. U to je doba na Krku postojao i veljotski jezik, krčki varijetet dalmatoromanskoga, pa se neki elementi mogu pripisati i tom starijem sloju. U tekstovima nalazimo i latinske izraze uobičajene u ondašnjim dokumentima.

19 To je stariji katastik koji spominje Polonijo.

20

Više vidi u URSINI 1998. 
Budući da je riječ o prijepisima, možemo sumnjati u autentičnost jezičnoga izraza i pretpostavljati da su prepisivači unosili jezične promjene. U nekoj je mjeri toga zasigurno bilo, ali s obzirom na to da je onima koji su prepisivali dokumente bila važna autentičnost sadržaja, smatramo da su i jezik nastojali zadržati autentičnim.

Jezičnu analizu započinjemo na ovdje predstavljenim tekstovima, ali je proširujemo dodatnim primjerima iz drugih talijanskih dokumenata u zborniku.

Kako smo već spomenuli, u talijanskom tekstu nalazimo i neke latinske riječi: perpetualiter, similiter, etiam, item, quondam. Osim toga, u nekim slučajevima grafija odgovara latinskom sustavu. Tako je često prisutno etimološko $h$ (koje se pisalo, ali se nije izgovaralo): havemo, havevo, heredi, huomini, ali nalazimo i forme bez $h$ (aver), pa čak i treće lice glagola avere bez $h(\grave{a})$. Fonem [ts] u intervokalnom položaju također nalazimo napisan u skladu s latinskom grafijom (condition).

U mletačkom, kao i u drugim sjevernotalijanskim dijalektima, prisutan je fenomen koji zahvaća bezvučne okluzive, a naziva se lenicijom. Manifestira se trima načinima: kao sonorizacija, frikativizacija i ispadanje. Tako nalazimo primjere s ozvučenim bezvučnim dentalnim okluzivima: bonificade, dada, dado, Fradelli (ali i Fratelli), intrada, servidori, Vedella. Frikativizaciju nalazimo u riječi cavedal ( $<$ CAPITALE).

Također, često nalazimo alveolarne afrikate ili frikative gdje su u talijanskom palatalni konsonanti: azonzer, camisotto, descazar, dusento (ali cento), rason (ali prevladava oblik ragion), zorno, Zorzi, Zuanne, zasendo (ali i giacendo), zera.

Infinitivi, kako je to uobičajeno u mletačkom, iskazani su bez završnoga vokala (magnificar, dar, azonzer, appar), u skladu sa sjevernotalijanskim fenomenom apokope - ispadanja završnoga vokala, što je prisutno i u drugim riječima (condition, dichiaration).

Ima primjera s izostankom diftongacije otvorenog $e$ i $o$ u otvorenom slogu, što je također odlika mletačkoga: fora 'izvan' (ali pojavljuje se i fuora).

Prevladavajući je oblik određene zamjenice muškoga roda $i l$, ali ponegdje nailazimo i na mletački oblik el: el qual avesse la Giesia nelle man. Prijedlog također nalazimo u varijantama de i di.

Dio oblika glagolske fleksije drugačiji je od današnjih (uglavnom je riječ o mletačkim formama, ali neke su bile prisutne i u starijem talijanskom): adimandemo, confermemo, debbia, fesse, havemo, piaqua. Karakteristični su mletački oblici futura i kondicionala, gdje vokal nije izmijenjen, niti eliminiran: accaderà, seminarà.

Nalazimo također karakterističnu mletačku upotrebu glagolskoga oblika za 3. lice, koji je isti u jednini i množini: li nostri Successori desse, ò donasse questa Giesia; che sia tenudi à dar; sia distribuiti per me alli poveri Vestimenti.

Što se leksičkih osobitosti tiče, možemo navesti nekoliko primjera: mo 'sada' (da mo avanti), devenga 'pripasti' (che la metà di tutti gli Beni predetti devenga 
al Monastero de San Francesco), galder 'uživati' (che Lui possa galder li Terreni di questa Giesia), kao i mletački privativni prefiks des-: descazar.

Nadalje, u oporuci Katarine Frankopan nalazimo riječ Iesia, dok je u drugim oporukama češći oblik, također mletački, Giesia, a rjeđe nalazimo i Chiesa. U jednom padovanskom tekstu iz 1494. rabi se oblik Iesia (pastor nostro dela sancta madre Iesia). ${ }^{21}$ U Rosamanijevu rječniku nalazimo leme iefia i iexia ${ }^{22}$, a obje su zabilježene na Cresu u 15. stoljeću.

U dokumentu o oltaru sv. Bernardina nalazimo oblike figlia 'kći' i figlio 'sin', koji odgovaraju današnjim talijanskim riječima. Međutim, u drugim su oporukama u zborniku prisutni i mletački oblici fiol $\left(241^{v}\right)$ i fiola $\left(271^{v}\right) .{ }^{23}$

Za ime Krka nalazimo u ovim dokumentima oblike Veggia i Veglia, nastale od VET(U)LA (scilicet CIVITATE). ${ }^{24}$

\section{Bibliografija}

Bartolijev zbornik krčkih isprava. Arhiv Provincije franjevaca konventualaca u Zagrebu.

BASSO, Walter, Dino DURANTE. 2000. Nuovo dizionario veneto-italiano etimologico. Villanova del Ghebbo: CISCRA.

BOERIO, Giuseppe. 1856. Dizionario del dialetto veneziano. Venezia: Giovanni Cecchini. Cattastico documentato del monastero di Veglia dei Min. Conv. dal 1284 al 1781. Knjižnica Samostana franjevaca trećoredaca glagoljaša u Krku.

CORNAGLIOTTI, Anna. 1988. Lingua e scrittura. U Lexikon der Romanistischen Linguistik, IV: Italienisch, ur. Günter Holtus, Michael Metzeltin, Christian Schmitt, 379-392. Tübingen: Niemeyer.

CORTELAZZO, Manlio. 1982. Il veneziano, lingua ufficiale della Repubblica?. U Guida ai dialetti veneti, ur. Manlio Cortelazzo, 59-73. Padova: CLEUP.

ČRNČIĆ, Ivan. 1867. Najstarija poviest krčkoj, osorskoj, rabskoj, senjskoj i krbavskoj biskupiji. Rim: P. Marietti.

ČRNČIĆ, Ivan. 1888. Što je pisama sakupio P. Blagoslav Bartoli. Starine JAZU 20: 1-21. Diplomatički zbornik Kraljevine Hrvatske, Dalmacije i Slavonije - Codex diplomaticus Regni Croatiae, Dalmatiae et Slavoniae. 1904-1990. Sv. 1-18. Zagreb: JAZU.

21 Navod prema VIDESOTT 2009: 38.

22 U ovom primjeru vidimo tipičnu mletačku upotrebu grafema $x$ za sonorni sibilant $[z]$.

23 Možemo spomenuti i druge rodbinske nazive u oporukama u zborniku. U svim se oporukama rabi talijanski oblik moglie 'žena', dok mletački oblik muier nalazimo nalazimo samo u jednoj oporuci (198) . Zanimljivo da je oporuku u kojoj je oblik muier oporučitelj Andrea Foietta, 'scrivan della Camera Fiscal de Veggia', napisao vlastoručno. Sonoriziran oblik marido nalazimo u jednom dokumentu $\left(198^{v}\right)$, dok je u ostalima oblik marito. Osim spomenutih, pristuni su i ovi nazivi: nepote $\left(241^{v}\right)$, nipote $\left(250^{\mathrm{r}}\right)$, nezza $\left(261^{\mathrm{v}}\right)$, fratello $\left(261^{\mathrm{v}}\right)$, sorella $\left(275^{\mathrm{v}}\right)$.

Dalmatoromanski je oblik Vekla. 
DOTTO, Diego 2008. Scriptae venezianeggianti a Ragusa nel XIV secolo. Edizione e commento di testi volgari dell'Archivio di Stato di Dubrovnik. Roma: Viella.

FERGUSON, Ronnie. 2007. A Linguistic History of Venice. Firenze: Leo S. Olschki Editore.

FOLENA, Gianfranco. 1970. Introduzione al veneziano „de là da mar“. Bollettino dell'Atlante linguistico mediterraneo 10-12: 332-376.

GALOVIĆ, Tomislav. 2009. Bartolijev zbornik (Collectanea Bartoliana) - dragocjeno vrelo za povijest grada i otoka Krka. Krčki kalendar 2010: 83-89.

Lexicon Latinitatis medii aevi Iugoslaviae, 1973-1978. Ur. M. Kostrenčić et. al. Zagreb: JAZU.

MAGDIĆ, Mile. 1900. Regesta nekojih izprava XIV. vijeka, koje je prepisao franjevac Felice Bartoli. Vjestnik Kr. hrvatsko-slavonsko-dalmatinskog zemaljskog arkiva 2: 20-26.

MARAZZINI, Claudio. 1994. Lingua italiana: profilo storico. Bologna: Il Mulino.

MARCATO, Carla. 2002. Il Veneto. U I dialetti italiani. Storia, struttura, uso, ur. Manlio Cortelazzo i dr., 296-328. Torino: UTET.

MARCATO, Gianna, Flavia URSINI. 1998. Dialetti veneti. Grammatica e storia. Padova: Unipress.

METZELTIN, Michele. 1988. Veneziano e italiano in Dalmazia. U Lexikon der Romanistischen Linguistik, IV: Italienisch, ur. Günter Holtus, Michael Metzeltin, Christian Schmitt, 551-569. Tübingen: Niemeyer.

MIOTTO, Luigi. 1991. Vocabolario del dialetto veneto-dalmata. Trieste: Lint.

PELLEGRINI, Giovanni Battista. 1977. Studi di dialettologia e filologia veneta. Pisa: Pacini.

ROŠČIĆ, Nikola Mate. 1983. Bartoli, Feliks. U Hrvatski biografski leksikon. Zagreb: Leksikografski zavod Miroslav Krleža. http://hbl.lzmk.hr/clanak.aspx?id=1371 (pristup 23. 7. 2015).

TOMASIN, Lorenzo. 2001. Il volgare e la legge. Storia linguistica del diritto veneziano (secoli XIII-XVIII). Padova: Esedra.

URSINI, Flavia. 1987. Sedimentazioni culturali sulle coste orientali dell'Adriatico: il lessico veneto-dalmata del Novecento. Atti e Memorie della Società Dalmata di Storia Patria 15: 20-179.

URSINI, Flavia. 1995. Sistemi linguistici in competizione sulla costa adriatica orientale: il veneto-dalmata tra gli idiomi romanzi e non romanzi dell'area balcanica in età moderna. U Italia settentrionale: crocevia di idiomi romanzi, ur. Emanuele Banfi, Giovanni Bonfadini, Patrizia Cordin, Maria Iliescu, 179-188. Tübingen: Niemeyer.

URSINI, Flavia. 1998. La lingua d'Italia sulle coste orientali dell'Adriatico fra Trecento e Quattrocento. U La „Lingua d'Italia“: usi pubblici e istituzionali. Atti del XXIX Congresso Internazionale di Studi della SLI (Malta 3-5 novembre 1995), ur. Gabriella Alfieri, Arnold Cassola, 324-339. Roma: Bulzoni.

VIDESOTT, Paul. 2009. Padania scrittologica. Analisi scrittologiche e scrittometriche di testi in italiano settentrionale antico dalle origini al 1525. Tübingen: Max Niemeyer Verlag.

ZAMBONI, Alberto. 1974. Veneto. Pisa: Pacini.

ZAMBONI, Alberto. 1988. Veneto. U Lexikon der Romanistischen Linguistik, IV: Italienisch, ur. Günter Holtus, Michael Metzeltin, Christian Schmitt, 379-538. Tübingen: Niemeyer. 
Documenti quattrocenteschi in lingua italiana del primo volume della Collectanea Bartoliana

Nel convento del Terzo Ordine Francescano della città di Krk (Veglia) sull'omonima isola croata si conserva una raccolta di documenti manoscritti dal Duecento all'Ottocento. Dato che la maggior parte dei documenti è stata raccolta e copiata da fra Felice Maria Bartoli, questa raccolta viene chiamata Collectanea Bartoliana (in croato Bartolijev zbornik). Si tratta di due codici che comprendono più di quattrocento fogli di carta scritti su ambedue le facce. Nel primo volume si trovano i documenti stesi in latino e in italiano, mentre nel secondo si trovano anche quelli croati, scritti in caratteri glagolitici (descrizione in GALOVIĆ 2009). Nella nostra comunicazione si analizzano i documenti in lingua italiana del primo volume stesi nel Quattrocento.

Il documento più antico di questa raccolta è un privilegio del „Conte Zuanne de Frangipanibus“ del 1445. (fol. 56r). Segue il „punto di testamento“ di sua moglie Elisabetta fatto nel 1484 a Venezia. L'ultimo in ordine cronologico è il riassunto di un documento latino del 1478 sull'altare di San Bernardino.

Conoscendo la lunga dominazione della Repubblica di Venezia e il notevole influsso linguistico, in molti testi della costa croata dei secoli passati, pur essendo scritti in varietà italoromanza di tipo toscano, si trovano vari elementi linguistici veneti. Il veneto era normalmente (spesso accanto al croato) la lingua della comunicazione quotidiana di molti abitanti dell'area concernente, e così anche delle persone che hanno scritto i documenti dei quali ci occupiamo. Perciò, come si può aspettare, nei testi analizzati troviamo diversi elementi veneti. Alcuni dei fenomeni sono ad esempio: sonorizzazione delle occlusive intervocaliche (bonificade, fradelli, tenudi), le affricate alveolari invece delle palatali (zorno, descazar, azonzer), caduta delle vocali finali (magnificar, dar, azonzer, appar, condition, dichiaration), forme verbali (havemo, debbia, seminarà, confermemo), forme caratteristiche dei nomi di persona (Zorzi, Zuanne).

Per la nostra analisi linguistica il punto di riferimento sono le descrizioni del veneziano (ZAMBONI 1974, 1988; PELLEGRINI 1977; CORTELAZZO 1982; MARCATO/URSINI 1998; MARCATO 2002; FERGUSON 2007; ZAMBONI 1974; Idem 1988) e del veneto-dalmata (FOLENA 1970; METZELTIN 1988; URSINI 1987; Idem 1995; Idem 1998) nonché le opere lessicografiche (BOERIO 1856; BASSO/DURANTE 2000; MIOTTO 1991). Ci serviamo anche dei libri che presentano e analizzano i documenti antichi veneziani (TOMASIN 2001; DOTTO 2008). 


\section{Documents in Italian Language from the $15^{\text {th }}$ Century in the First Volume of the Collectanea Bartoliana}

A manuscript collection of copied documents dating from the $13^{\text {th }}$ to $19^{\text {th }}$ century, usually called the Collectanea Bartoliana (Bartolijev zbornik in Croatian) in the specialist literature since the documents were collected and copied by Fra Felice Maria Bartoli, is stored in the monastery of Glagolitic tertiary Franciscans in Krk. It consists of two volumes numbering altogether over 400 pages of paper written on both sides. The first volume contains documents in Latin and Italian language, whereas the second one has also some written in the Croatian language and Glagolitic script (description in GALOVIĆ 2009). The present paper gives a description of the documents from the $15^{\text {th }}$ century written in Italian language giving indications of their content and pointing out some of their language features.

The oldest document of the Collection is a privilege „Conte Zuanne de Frangipanibus" from 1445 (fol. 56r). It is followed by a fragment of a will by the count's wife Elizabeth who made it in 1484 in Venice. The last in chronological order is a summary of a Latin document from 1478 on the altar of Saint Bernard.

Given the long domination of the Venetian Republic and the considerable linguistic influence, in many texts from the Croatian coast dating from past centuries, despite being written in the Tuscan type of the Italo-Romance there are several Venetian linguistic elements. The Venetian was normally (often next to Croatian) a language of everyday communication for many inhabitants of the area in question, and thus for the people who composed the documents that are examined here. As one might expect, there are different Venetian elements in the analyzed texts. Some linguistic phenomena are for example: occlusive intervocalic sounds (bonificade, fradelli, tenudi), alveolar instead of palatal affricates (zorno, descazar, azonzer), drop of the final vowels (magnificar, dar, azonzer, appar, condition, dichiaration), verb forms (havemo, debbia, seminarà, confermemo), the characteristic forms of personal names (Zorzi, Zuanne).

A point of reference for this linguistic analysis are descriptions of the Venetian (ZAMBONI 1974, 1988; PELLEGRINI 1977; CORTELAZZO 1982; MARCATO/URSINI 1998; MARCATO 2002; FERGUSON 2007; ZAMBONI 1974; Idem 1988) and the Venetian-Dalmatian languages (FOLENA 1970; METZELTIN 1988; URSINI 1987; Idem 1995; Idem 1998) as well as lexicographical works (BOERIO 1856; BASSO/DURANTE 2000; MIOTTO 1991). The books that offer and analyze the old Venetian documents have also been used (TOMASIN 2001; DOTTO 2008). 
Parole chiave: catastico, Quattrocento, lingua italiana, elementi veneti, Felice Maria Bartoli Keywords: catastico (cadastre), $15^{\text {th }}$ century, Italian language, Venetian elements, Felice Maria Bartoli

Ključne riječi: katastik, 15. stoljeće, talijanski jezik, mletački elementi, Feliks Marija Bartoli

Vinko Kovačić

Filozofski fakultet Sveučilišta u Zagrebu

HR-10000 Zagreb, Ivana Lučića 3 vkovacic@ffzg.hr 


\section{FILOZOFSKI FAKULTET SVEUČILIŠTA U ZAGREBU \\ ZAVOD ZA HRVATSKU POVIJEST \\ INSTITUTE OF CROATIAN HISTORY \\ INSTITUT FÜR KROATISCHE GESCHICHTE}
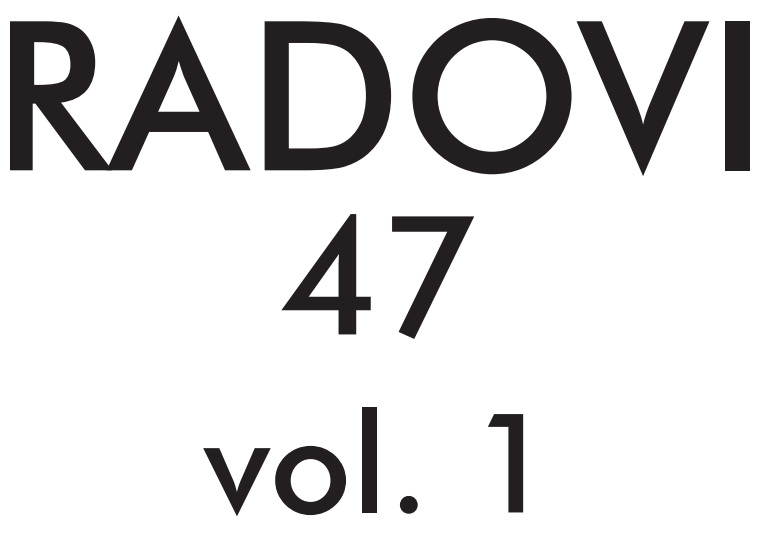

ZAVOD ZA HRVATSKU POVIJEST

FILOZOFSKOGA FAKULTETA SVEUČILIŠTA U ZAGREBU

\section{PF press \\ ZAGREB 2015.}




\title{
RADOVI ZAVODA ZA HRVATSKU POVIJEST FILOZOFSKOGA FAKULTETA SVEUČILIŠTA U ZAGREBU
}

\author{
Knjiga 47, vol. 1
}

\author{
Izdavač / Publisher \\ Zavod za hrvatsku povijest \\ Filozofskoga fakulteta Sveučilišta u Zagrebu \\ FF-press \\ Za izdavača / For Publisher \\ Vlatko Previšić \\ Glavni urednik / Editor-in-Chief \\ Hrvoje Gračanin \\ Izvršna urednica / Executive Editor \\ Inga Vilogorac Brčić \\ Uredništvo / Editorial Board
}

Bruna Kuntić-Makvić (stara povijest/ancient history), Zrinka Nikolić Jakus (srednji vijek/ medieval history), Hrvoje Petrić (rani novi vijek/early modern history), Željko Holjevac (moderna povijest/modern history), Tvrtko Jakovina (suvremena povijest/contemporary history),

Silvija Pisk (mikrohistorija i zavičajna povijest/microhistory and local history),

Zrinka Blažević (teorija i metodologija povijesti/theory and methodology of history)

Međunarodno uredničko vijeće / International Editorial Council

Denis Alimov (Sankt Peterburg), Živko Andrijašević (Nikšić), Csaba Békés (Budapest), Rajko Bratož (Ljubljana), Snježana Buzov (Columbus, Ohio), Svetlozar Eldarov (Sofija), Toni Filiposki (Skopje), Aleksandar Fotić (Beograd), Vladan Gavrilović (Novi Sad), Alojz Ivanišević (Wien),

Egidio Ivetić (Padova), Husnija Kamberović (Sarajevo), Karl Kaser (Graz),

Irina Ognyanova (Sofija), Géza Pálffy (Budapest), Ioan-Aurel Pop (Cluj),

Nade Proeva (Skopje), Alexios Savvides (Kalamata), Vlada Stanković (Beograd), Ludwig Steindorff (Kiel), Peter Štih (Ljubljana)

Izvršna urednica za tuzemnu i inozemnu razmjenu / Executive Editor for Publications Exchange Kristina Milković

Tajnik uredništva / Editorial Board Assistant

Dejan Zadro

Adresa uredništva/Editorial Board address

Zavod za hrvatsku povijest, Filozofski fakultet Zagreb, Ivana Lučića 3, HR-10 000, Zagreb

Tel. ++385 (0)1 6120 150, 6120 158, faks ++385 (0)1 6156879

Časopis izlazi jedanput godišnje / The Journal is published once a year

Časopis je u digitalnom obliku dostupan na / The Journal in digital form is accessible at Portal znanstvenih časopisa Republike Hrvatske „Hrčak“ http://hrcak.srce.hr/radovi-zhp

Financijska potpora za tisak časopisa / The Journal is published with the support by

Ministarstvo znanosti, obrazovanja i športa Republike Hrvatske

Časopis je indeksiran u sljedećim bazama / The Journal is indexed in the following databases:

Directory of Open Access Journals, EBSCO, SCOPUS, ERIH PLUS 
Naslovna stranica

Iva Mandić

Grafičko oblikovanje i računalni slog

Marko Maraković

Lektura

Samanta Paronić

Tisak

Web2tisak, Zagreb

Naklada

250 primjeraka

Časopis je u digitalnom obliku dostupan na Portalu znanstvenih časopisa Republike Hrvatske ,Hrčak“ http://hrcak.srce.hr/radovi-zhp

The Journal is accessible in digital form at the Hrcak - Portal of scientific journals of Croatia http://hrcak.srce.hr/radovi-zhp 


\section{RADOVI 47}

\section{vol. 1}

ZaVoda za hrVAtSku poviJest FILOZOFskoga fakulteta SVeuČILIŠTA u Zagrebu 


\title{
Tematski blok / Themed issue
}

\section{TREĆOREDSKA GLAGOLJAŠKA TRADICIJA U EUROPSKOM KONTEKSTU TERTIARY GLAGOLITIC TRADITION IN EUROPEAN CONTEXT}

\author{
Radovi međunarodnoga znanstvenog skupa \\ održanoga 27. i 28. IX. 2013. na Hrvatskom katoličkom sveučilištu u Zagrebu \\ u organizaciji \\ Provincije franjevaca trećoredaca glagoljaša u Zagrebu, Hrvatskoga katoličkog \\ sveučilišta u Zagrebu, Filozofskoga fakulteta Sveučilišta u Zagrebu - Odsjek za \\ povijest, Filozofskoga fakulteta Sveučilišta u Splitu - Odsjek za povijest, Instituta \\ za povijest umjetnosti u Zagrebu i Staroslavenskoga instituta u Zagrebu \\ Proceedings of the International Scientific Conference \\ held on 27th and 28th September 2013 at the Catholic University of Croatia in Zagreb \\ and organized by \\ the Province of the Glagolitic Friars of the Third Order Regular, Catholic University \\ of Croatia in Zagreb, Faculty of Humanities and Social Sciences of the University \\ of Zagreb - Department of History, Faculty of Humanities and Social Sciences of \\ the University of Split - Department of History, Institute of Art History, \\ and Old Church Slavonic Institute
}

Gosti urednici / Guest editors

\author{
Ivan BOTICA \\ Tomislav GALOVIĆ \\ Kristijan KUHAR
}

